Gazi University
Journal of Science
http://dergipark.gov.tr/gujs

\title{
Fractal Dimension of Streetscape as a Proxy to the Design Dimension of the Built Environment in Walkability Research
}

\author{
Maghsoud GHANAT BARI* (D), Ayse TEKEL \\ Department of Urban and Regional Planning, Faculty of Architecture, Gazi University, Ankara, Turkey
}

Highlights

- Participation of different disciplines in walkability research.

- Examining the relationship between walking behavior and the built environment.

- Fractal dimension of streetscape as a variable in walkability research.

\begin{tabular}{l} 
Article Info \\
\hline Received: 16 Apr 2020 \\
Accepted: 23 Aug 2021 \\
Keywords \\
Walkability \\
Fractal dimension \\
StreetScape features \\
GIS \\
Planning
\end{tabular}

\section{INTRODUCTION}

Walking is a common form of physical activity with documented benefits. Among those are being the simplest, cheapest, least harmful mode of transportation, improving the quality of life, and providing opportunities for socialization [1-4]. Walking is done for both recreation purposes and to reach a destination. The latest one has diverse labeling; active travel, non-motorized travel, transport-related physical activity, destination-oriented walking, and utilitarian walking [1-14]. Walking behavior has been identified as being influenced by a number of criteria such as; individual, interpersonal/cultural, environmental, regional or national policy, and global factors. Ecologic models have been used to understand how these factors influence and ultimately lead to the development of comprehensive interventions to promote walking [15-20].

The built environment factor has gained importance as it has an ability to support or prevent walking behavior [21] via its various components at different spatial units [22,23]. To create environments that promote walking, it is necessary to identify specific characteristics of those places that correlate with walking [12], and discovering those elements could lead to the planning of places with emphases on those particular elements [9]. The built environment is a multidimensional concept that comprises of urban design, land use, and transportation systems [12,22-24]. Multiple attempts have been made to characterize these components by using appropriate attributes at the different spatial units that affect walking behavior. To some, physical space conditions offer the most optimal situation for walking. These conditions represented in terms of D dimensions (Density, Diversity, and Design) and measured with the 3Ds framework $[25,26]$. Others see the number, or type of destination, or total walking distance, and time as the

*Corresponding author, e-mail: maghsoud.ghanat@gmail.com 
most critical conditions for determining the best situation for walking. These conditions are operationalized with the distance-oriented walkability or 3D+R framework [27-29]. There is also the belief that qualitative aspects of the built environment offer the best situation for walking, and these aspects are measured by streetscape features [30,31]. Examining the relationship between physical activity and the built environment has recently increased [12], but the building blocks of this correlation are approached differently by transportation planning and urban design experts (Table 1).

Table 1. Different approaches to physical activity and built environment

\begin{tabular}{|c|c|c|c|}
\hline Building Blocks & Different approaches & Transportation planning & Urban design \\
\hline $\begin{array}{l}\text { Physical activity and } \\
\text { walking behavior }\end{array}$ & $\begin{array}{c}\text { The outcome of walking } \\
\text { behavior }\end{array}$ & Amount of walking & Quality of walking \\
\hline & $\begin{array}{l}\text { Attributes of built environment } \\
\text { correlate with walking behavior }\end{array}$ & $\begin{array}{l}\text { Macro-scale attributes correlate } \\
\text { with the amount of walking }\end{array}$ & $\begin{array}{l}\text { Micro-scale attributes correlate } \\
\text { with the quality of walking }\end{array}$ \\
\hline Built environment & $\begin{array}{c}\text { Attribute as a proxy for the } \\
\text { design dimension of the built } \\
\text { environment }\end{array}$ & $\begin{array}{l}\text { Street intersections with } \\
\text { emphasize on the link function of } \\
\text { the streets }\end{array}$ & $\begin{array}{l}\text { Streetscape features with the } \\
\text { emphasize on the place function } \\
\text { of the streets }\end{array}$ \\
\hline
\end{tabular}

The first difference approach relates to the expected final results of walking behavior. The main objective of transportation planning is to improve the system efficiency. They give priority to the needs of motor vehicles, but have a negative view of pedestrians because they slow the flow of vehicles [32]. In their studies, physical activity and walking behavior are categorized as a mode of travel behavior, and there are attempts being made to prioritize this mode of travel above all others [22]. Transportation planners are also interested in walking because it helps to ease traffic congestion, air pollution, and problems related to traffic such as pedestrian injuries [16]. Their main focus is not necessarily for the pedestrian but rather improving system efficiency, and attempts are correlated with the amount of walking [33]. As walking increases, so do the benefits that are derived from it. Urban designers on the other hand, try to measure the final result of walking, not just by the number or duration of trips, but also by the quality of those trips in terms of user experience. Urban designers have a positive view of pedestrians, and they are interested in walking as it increases the quality of life, user experience, way of socialization, and enhancing the sense of community $[16,20,33]$. Attempts are being made to create an environment where walking becomes the preferred choice, and attempts are correlated with the quality of those behaviors [33]. As this behavior increases the benefits will not only be physical but also psychological. They apply the quality of walking behavior in subjective analysis, but they do not have such data in objective analysis, so they have to use the amount of walking to compelet their analysis [31] (Table 2). The key focus of transportation planners is to increase the amount of walking, while urban designers are focused on the quality of walking and not just the degree that walking is used to get from one place to another.

Table 2. The expected result of walking behavior in different type of analyses

\begin{tabular}{lccc}
\hline & Analyze Type & Transportation Planning & Urban Design \\
\hline & Objective & Amount of walking (pedestrian count) & Amount of walking \\
\cline { 2 - 4 } & Subjective & $\begin{array}{c}\text { Amount of walking (duration of } \\
\text { activity) }\end{array}$ & Quality of walking \\
\hline
\end{tabular}

The second approach relates to attributes of the built environment, used as a proxy to identify its effects on walking behaviors. Transportation planning gave rise to $3 \mathrm{D}$ and $3 \mathrm{D}+\mathrm{R}$ frameworks by conceptualizing and measuring the built environment effects on travel behaviors $[16,25,34]$ which later were adapted into the walkability research $[8,9,26-29,35]$. In these studies, abstract function and efficiency-oriented aspect of the built environment at large spatial units like city and region are represented by straightforward attributes that reveal the effect of the built environment on the amount of walking [36]. But other attributes that correlate with the quality of the built environment and user perceptions have been largely underestimated [32]. The focus of urban design is the characteristics of the built environment which effect the pedestrian experience, with the primary focus on the concrete experiential qualities of the built environment at small to medium spatial units with aesthetic orientation [22]. To designer, micro-scale features of the built environment, especially the streetscape features, are better for determining the influence of the built environment on pedestrian experiences $[3,30,31,33,35,36]$ (Table 3). 
Table 3. Attributes that have effects on walking behavior

\begin{tabular}{|c|c|c|c|c|c|c|c|}
\hline & Scale & $\begin{array}{c}\text { Data } \\
\text { Source }\end{array}$ & Extracted Data & $\begin{array}{c}\text { Extraction } \\
\text { Purposes } \\
\end{array}$ & Variables & index & Disciplines \\
\hline \multirow{3}{*}{ 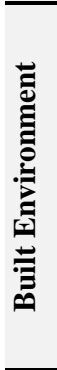 } & \multirow{2}{*}{ Macro } & \multirow{2}{*}{$\begin{array}{l}\text { Land use } \\
\& \\
\text { Zoning } \\
\text { data }\end{array}$} & $\begin{array}{l}\text { Proportion of } \\
\text { activities }\end{array}$ & $\begin{array}{l}\text { Represent urban } \\
\text { form (density, } \\
\text { diversity, design) } \\
\end{array}$ & $\begin{array}{c}\text { Residential, land use mix, } \\
\text { and street intersection } \\
\text { densities } \\
\end{array}$ & $3 \mathrm{D}$ & $\begin{array}{c}\text { Transportation } \\
\text { planning, Urban } \\
\text { design } \\
\end{array}$ \\
\hline & & & $\begin{array}{l}\text { Number of } \\
\text { activities }\end{array}$ & $\begin{array}{l}\text { Represent urban } \\
\text { form, routes } \\
\text { attributes }\end{array}$ & $\begin{array}{c}\text { Different land-use } \\
\text { activities, route attributes }\end{array}$ & $3 \mathrm{D}+\mathrm{R}$ & $\begin{array}{c}\text { Transportation } \\
\text { planning, urban } \\
\text { design } \\
\end{array}$ \\
\hline & Micro & $\begin{array}{l}\text { Urban } \\
\text { Design } \\
\text { data }\end{array}$ & $\begin{array}{l}\text { Design elements } \\
\text { (path, edge, } \\
\text { district, node, } \\
\text { landmark) } \\
\end{array}$ & $\begin{array}{l}\text { Represent path } \\
\text { component }\end{array}$ & $\begin{array}{c}\text { Streetscape features } \\
\text { (Imageability, enclosure, } \\
\text { human scale, transparency, } \\
\text { complexity) }\end{array}$ & $\begin{array}{l}\text { Streetscape } \\
\text { features }\end{array}$ & Urban design \\
\hline
\end{tabular}

The third approach relates to the function of a proxy of the built environment used to represent its design dimension. Since 1930, street and roads have been designed in two separate directions, one branch specialized in technical aspect of transportation planning [3]. Road and streets stripped from their former activities, started to serve one activity oriented to cars; and now are categorized as collectors, distributors, arterials, by-pass, highways, motorways, inner ring road, relief roads, and expressways. They were designed to be featureless landscapes, without any specific details to avoid attracting attention; making details less important as they become blurred by the speed of the machine [37]. This profession promoted a situation in which the flow of traffic became priority, followed by parking and loading, and with other activities becoming the lowest priority. Instead of giving equal consideration to the functions of road and streets, the emphasis was given to the link function of streets $[3,38]$. The other profession of road and streets design specialized in place-based design [3]. Several criticisms arouse that brought back the former activities, one of these came from Jane Jacobs [37] as a commentator she considered the streets to be the most important part of the built environment, making them the most vital organ in a city. Based on Jane Jacobs if a city's streets look interesting, the city looks interesting, and if they look dull, the city looks dull [39]. In another influential work, Kevin Lynch identified five concepts of a city. The first one of those concepts are the paths. He defined them as the network of the habitual or potential line of movement through the urban complex. He saw them as the most important elements of a city by which the whole can be ordered [40]. Urban designers have tried to bring back the former activities of the streets [37], yet instead of giving equal consideration to the functions of the streets, their emphasis was on the place function of the streets $[3,38]$.

Different intellectual traditions tend to disagree when it comes to measurement and analysis because the two traditions focus on measuring different aspects of the same behavior (Table 1). Some argue that the outcome of walking behavior should also be measured by the quality of walking behaviors not merely by the amount of those behaviors [33]. The contemporary characteristics of the built environment in walkability research cannot exhibit its effects on the pedestrian experience, and micro-scale features of the built environment could reveal them [3,30,31,33,35,36]. Moreover, the focus is on the presence of a variable or neighborhood attribute rather than its quality [41]. In this case, individual urban design features seldom prove significant in walking behaviors because multiple design features have a collective impact on walking behaviors [36]. Others argue that it is hard to implement micro-scale attributes of the built environment along with their macro-scale attributes [22,25]. The fractal dimension value of streetscape offers a potential solution to proposed arguments. Micro-scale attributes of the built environment could be implemented in walkability research, especially those believed to affect the preference and perception of the pedestrian. Besides this, it offers a way to implement both micro-scale and macro scale attributes of the built environment simultaneously.

The fractal dimension value of street vistas is one of the important tools used by urban designers to evaluate the visual quality of the street view (streetscape). Fractal is used to describe objects that are too irregular to fit into a traditional geometrical setting. The concept introduced by Mandelbort in 1977 as he suggests that the 'natural' world cannot be properly defined using only one, two or three dimensional Euclidean geometry. He developed this concept to explain the complexity of nature calling it the geometry of nature [42-47]. Fractal dimension ' $\mathrm{D}$ ' is used as a parameter to identify and quantify the fractal of patterns by expressing them as a number. This parameter describes how the patterns occurring at different magnifications combine to build the resulting fractal shape. The ' $\mathrm{D}$ ' value for Euclidean shapes like points, lines, planes, and solids, 
is a familiar concept described by ordinal integer values of $0,1,2$, and 3 respectively. The ' $\mathrm{D}$ ' value for fractal patterns is a non-integer number that lies between 1 and 2 . As the irregularity and detail level of a pattern increase the value approaches 2 and as the details decrease the value approaches 1 . Different techniques were proposed for calculating fractal dimension. The most popular ones are the Hausdorff dimension, box-counting dimension, self-similarity dimension, and correlation dimension. The boxcounting method is widely used to measure fractal dimension due to ease of implementation. In addition, it has been found to be suitable for architecture and urban analysis [46]. Fractal dimension has been implemented in many studies, and was successful at capturing the preference of the users in the natural environment [42,43], built environment [43], and the visual qualities of street vistas [44-46]. However, not all fractals are equally preferred. It is emphasized that the fractal dimension value of 1.3 is common in natural landscapes and fractals with fractal dimensions in the mid-range value of $1.3-1.5$ are naturally perceived and preferred. Values of less than 1.3 or more than 1.6 were found to have low preference [4246]. If the fractal structure is reflected in urban spaces as the geometric language of nature, it positively affects the visual quality of the city. Spaces with fractal qualities psychologically induce feelings such as peace, pleasure, satisfaction, comfort and happiness in the individual [47].

\section{METHOD}

This study aimed to analyze the effects of street design on utilitarian walking by identifying the main built environmental factors. The fractal dimension value of streetscape, which represents the value of the street view, is assumed to be the main factor affecting utilitarian walking. To test this hypothesis, it was necessary to find a place in an urban context that is used regularly for this type of walking, that provides opportunities to collect information about the paths from the users. Keçiören district was selected for this case study as it ranks first based on the population compared to other district of the metropolitan area of Ankara. Moreover, the subway stations in this district are located in neighborhoods that are heavily dominated by residential units. These stations are being reached by walking, and are mostly used by their inhabitants. It was important to gather information from the people living there as they knew the place very well, and used the path to reach to the station. Dutluk subway station, located in Keçiören district of Ankara, was selected for analyses after carrying out separate analyses. Objective analyses were carried out using land-use data along with data on restaurants, markets, bus stops, parks or green areas, schools, hospitals, street trees, residential units, and street photos. Subjective analysis data was collected through a survey conducted using 150 people all of whom used the Dutluk station (Table 4).

Table 4. Method of the study

\begin{tabular}{|c|c|c|c|c|c|c|}
\hline Step & Analyze & Purpose & Index & Attributes & Scale & Data Type \\
\hline 1 & Objective & $\begin{array}{c}\text { Identifying the } \\
\text { most walkable } \\
\text { neighborhood and } \\
\text { station }\end{array}$ & $3 \mathrm{D}$ & $\begin{array}{c}\text { Residential, } \\
\text { Land use mix, } \\
\text { Street intersection densities }\end{array}$ & $\begin{array}{l}\text { Neighborhood, } \\
400 \text {-meters } \\
\text { catchment area }\end{array}$ & Land use \\
\hline 2 & Objective & $\begin{array}{l}\text { Identifying the } \\
\text { value of routes } \\
\text { for walking }\end{array}$ & $3 \mathrm{D}+\mathrm{R}$ & $\begin{array}{l}\text { Restaurants, markets, bus stops, Parks or } \\
\text { green area, school, hospital, street trees, } \\
\text { residential building, street intersection } \\
\text { densities }\end{array}$ & $\begin{array}{c}\text { 400-meters } \\
\text { catchment area }\end{array}$ & $\begin{array}{l}\text { Field study, } \\
\text { Land use }\end{array}$ \\
\hline 3 & Objective & $\begin{array}{l}\text { Adding the fractal } \\
\text { dimension } \\
\text { variable to the } \\
\text { value of routes }\end{array}$ & $3 \mathrm{D}+\mathrm{R}$ & $\begin{array}{l}\text { Restaurants, markets, bus stops, Parks or } \\
\text { green area, school, hospital, street trees, } \\
\text { residential building, street intersection, } \\
\text { fractal dimension densities }\end{array}$ & $\begin{array}{c}\text { 400-meters } \\
\text { catchment area }\end{array}$ & $\begin{array}{l}\text { Field study, } \\
\text { Land use }\end{array}$ \\
\hline 4 & Subjective & $\begin{array}{l}\text { Validation of } \\
\text { results }\end{array}$ & - & Indices results, participant's opinion & $\begin{array}{l}\text { 400-meters } \\
\text { catchment area }\end{array}$ & $\begin{array}{c}\text { Survey, } \\
\text { Indices results }\end{array}$ \\
\hline
\end{tabular}

Land-use data was collected from Keçiören municipality. All other data needed for the analysis was collected through field study by authors. The objective analysis consists of three steps. In the first step two separate suitability analysis were conducted to rank 15 neighborhoods and 5 stations to identify the most walkable and also to locate a study area. Neighborhoods of Keçiören district of Ankara were selected because their land use was dominated by residential units and stations were accessible to be used by the residents of these neighborhoods. The 3D index developed by Frank et al. [26] was used as the procedure 
of measuring walkability in this step with the methods for calculating walkability index being reported elsewhere [9-11,26,48]. In summary, data on the residential units, street intersections, and land use mix extracted from land-use data and their densities were then calculated in ArcGIS tools (Figure 1). The ratio of residential units to the area allocated for residential use in a hectare was then used to calculate net residential density. The number of intersections with three or more intersecting streets in a square kilometer was used to measure intersection density, and land-use mix was calculated by using the following entropy index $[9-11,26,48]$ :

$$
-\frac{\sum\left(p_{k} \operatorname{Inp}_{k}\right)}{\operatorname{In}_{N}}
$$

where; $k=$ the category of land-use and $p=$ the proportion of the land area within a neighborhood allocated to especific land-use. The land-use of this study area was classified into five categories; residential, commercial, recreational, institutional, and others. If the result of the index (ranges between 0 and 1) is close to one, then it indicates a higher level of mixed uses in a given neighborhood. The density values of intersection, residential, and land-use mix are then normalized by Z-score. Later, the walkability index was derived from the sum of scores. The walkability index was calculated by using the following expression:

\section{$"$ Walkability $=[(Z$-score intersection density $)+(Z$-score residential density $)+(Z$-score land-use mix density)]".}

The density values of intersection, residential, land-use mix, and the result of walkability index was classified into 1 to 5 scores by using the normal distribution method in ArcGIS tools with 1 indicating low suitability and 5 indicating high suitability. Before starting the next analysis, the catchment area around the stations located inside the neighborhoods were set to 400 meters. If a person walks at a speed of 4800 meters in an hour this is equal to 400 meters or 5 minutes of walking. Both the Euclidian and Network distance method were applied to find the 400 meters' catchment areas for the stations. The catchment area created by Euclidian distance was selected for the analysis because it covered more street which in turn gave more opportunity to collect information concerning fractal dimension value. In addition, it made covering the route of the pedestrians much easier (Figure 2).

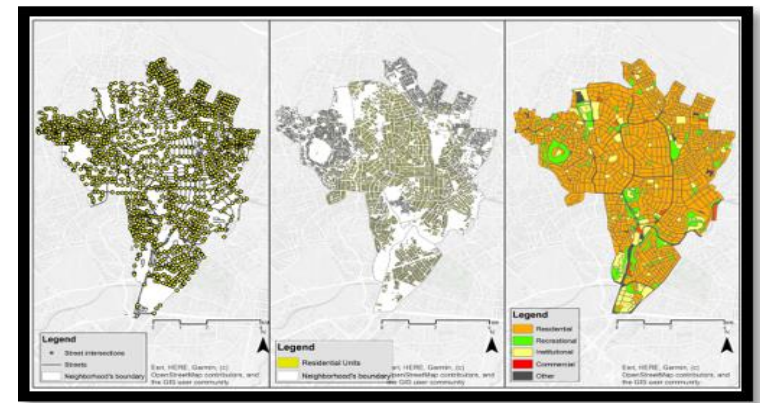

Figure 1. Street intersection, residential units, and land-use mix data

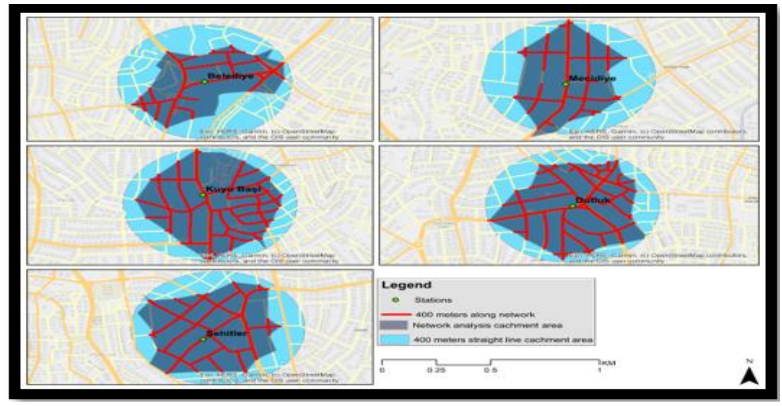

Figure 2. 400 meters' catchment area around stations

After setting the study area boundary, we followed the same procedure to create the variable needed to build the walkability index for stations. Based on the result of the analyses, the Dutluk station was found to be located close to the neighborhoods with diverse walkability scores, giving it the highest walkable score in the 400-meter's catchment area. This is why Dutluk station was selected for in depth research pertaining to this article and will continue to be referenced to later on (Figure 3).

In the second step, the 3D+R index, developed by Lee and Moudon [29], was used to analyze the suitability of the routes for walking inside the 400-meters catchment area surrounding Dutluk station with the procedure for calculating this index being reported elsewhere [29,35]. To apply the analysis, Dutluk station was considered as the endpoint of walking journeys. Then, the area inside the 400 -meters radius around the 
station was considered as the catchment area of the endpoint. The total number of restaurants, markets, bus stops, parks or green areas, schools, hospitals, street trees, residential building inside the catchment area were collected and then were classified as the activity and land-use of origin and destination component. In addition, the total number of street intersections inside this area were collected and then were classified as the accessibility of path component. The data was collected through a field study. Then variables which included restaurants, market, bus stops, school, hospital, street trees, residential building inserted as a point features in ArcGIS tools. Data on park or green areas were inserted as point features using their area size, then their densities were calculated using Kernel Density with the resulting cell size being 3.2*3.2. A total of 9 raster dataset was created and then reclassified to have a score range of 1-5 by using the normal distribution method in ArcGIS tools. The walkability index was obtained through combining these raster databases (Figure 4). The walkability index was calculated by using the following expression:

$$
\begin{aligned}
“ \text { Walkability }= & {[(\text { restaurants })+(\text { markets })+(\text { bus stops })+(\text { parks or green areas })+(\text { schools })+} \\
& (\text { hospitals })+(\text { street trees })+(\text { residential building }) ' s \text { density })+(\text { intersection density })] " .
\end{aligned}
$$

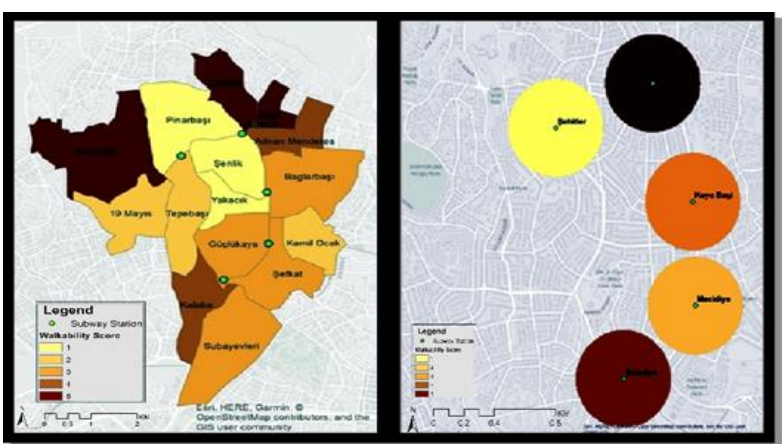

Figure 3. Suitability analyses for walking

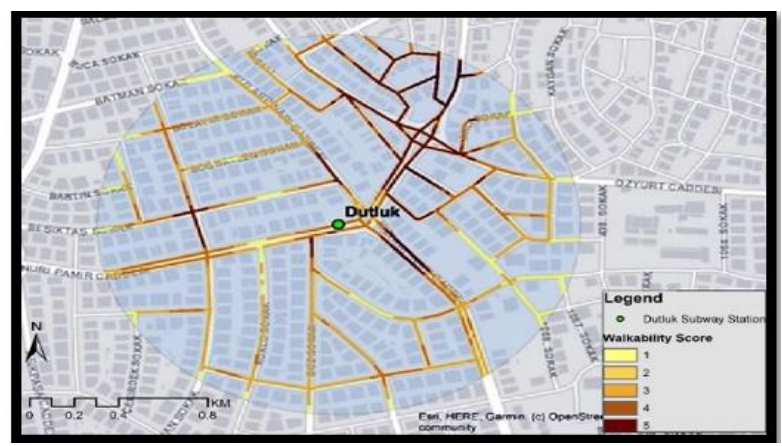

Figure 4. Suitability of routes for walking

In the third step, the fractal dimension value of streetscapes was collected to evaluate the visual value (visual quality) of all streets within the 400-meters catchment area, and then were used to build another suitability index. Concerns arouse because the authors of this article was unfamiliar with the participant routes and whether the participant would use all of the street or part of street to reach their destinations. Before conducting survey and collecting any data about participant routes, the data had to be collected in a way that took this into account. To start, street pictures were needed. To obtain the pictures, intersections were carefully selected because the intersections are the beginnings of streets, and new visual vistas start or end at these points. Besides this, pedestrians are highly likely to change their routes at these points; also, pedestrian's awareness are high due to the high likelihood of encountering with barriers such as traffic accidents. 57 street intersections were identified within the catchment area of the Dutluk station and then were classified into two categories: intersections formed by narrow streets, and intersections formed by wide streets and roads. A buffer feature with a 10-meter radius (average of street widths) was created around the intersections in the first category, and a buffer with a 15-meter radius was created around the intersections in the second category. Based on the characteristics of the intersections, 3 or 4 points were added to the buffers. 3 points had been added to the three-way intersections and 4 points had been added to the four-way intersections. Also, two points with an opposite view (with a 180 angle opposite to each other) were added to the middle of the streets as they were considered too long in length. A total of 240 points have been identified in ArcGIS tools for the locations to take pictures. Pictures of the designated points at the site were taken later in the evening in order to avoid sunlight or shadow affecting the quality of the photos by the authors (Figure 5). First, pictures were edited. The pixel size of the pictures was set to $480 * 360$, and then the sky portion of the pictures was removed because it affects the fractal dimension value, as the fractal dimension of the built environment was important for this study. The fractal dimension value of the pictures was calculated by the box-counting method in the HarFa 5.5 program (Figure 6). 


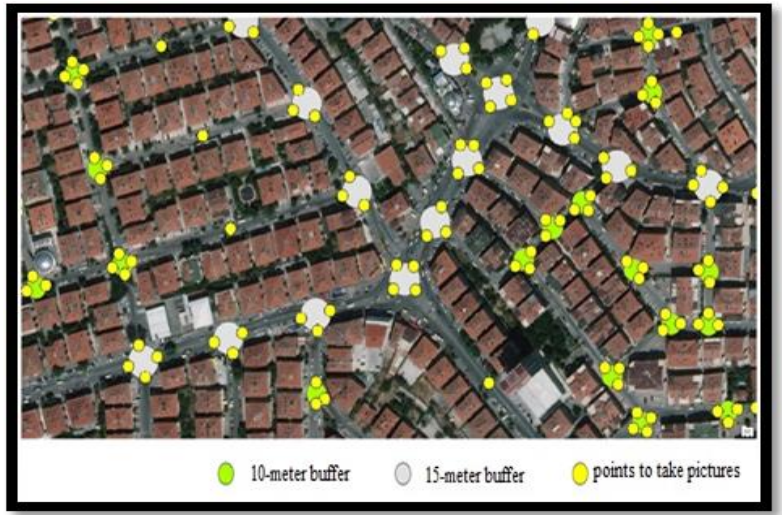

Figure 5. Steps followed to take the pictures

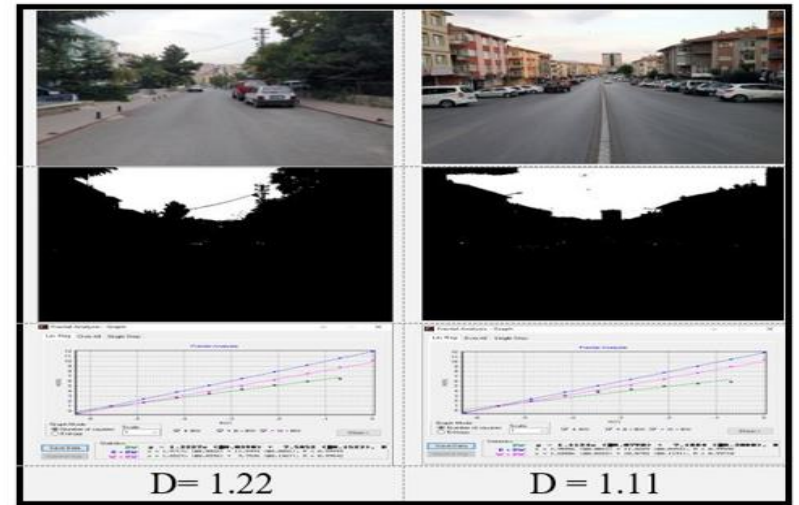

Figure 6. Fractal dimension calculation

The fractal dimension value of all pictures were less than 1.3. The value for the 46 streets inside the catchment area ranged from lowest of 1.12 and highest of 1.27, and the mean fractal dimension value of the streets was 1.18 (Table 5). After getting the value of the streets, another process was carried out on the fractal dimension database in order to collect the route values. The streets were divided into segments at the intersections. The fractal dimension value of all pictures were added to the street segments in ArcGIS tools. Each Street segment in the study area has two pictures and the mean fractal dimension value of two pictures were added to the fractal dimension value of the street segments.

Table 5. Fractal dimension value (D) of streets inside the catchment area of Dutluk station

\begin{tabular}{|cccccccccc|}
\hline Street Name & $\boldsymbol{D}$ & Street Name & $\boldsymbol{D}$ & Street Name & $\boldsymbol{D}$ & Street Name & $\boldsymbol{D}$ & Street Name & $\boldsymbol{D}$ \\
\hline 1065 & 1.23 & 1076 & 1.15 & Yılmaz & 1.18 & Bolayır & 1.20 & Bektaşoğlu & 1.17 \\
1066 & 1.20 & 1077 & 1.15 & Arlı & 1.17 & Buket & 1.19 & Anavatan & 1.14 \\
1067 & 1.23 & 1078 & 1.27 & Baldıran & 1.20 & Burgu & 1.20 & Gülbaba & 1.13 \\
1068 & 1.18 & 1079 & 1.18 & Bartın & 1.20 & Çekirdek & 1.22 & Kızlarpınarı & 1.15 \\
1070 & 1.19 & 1080 & 1.25 & Batman & 1.20 & Çit & 1.18 & Nuri Pamir & 1.17 \\
1071 & 1.18 & 1081 & 1.25 & Beşiktaş & 1.20 & Dadaş & 1.24 & Özyurt & 1.18 \\
1072 & 1.20 & 1082 & 1.12 & Beyaz & 1.19 & Doğangün & 1.19 & & \\
1073 & 1.19 & 1086 & 1.24 & Beyler & 1.20 & Düz & 1.14 & & \\
1074 & 1.18 & 1112 & 1.18 & Biricik & 1.21 & Köklü & 1.21 & & \\
1075 & 1.15 & 1113 & 1.19 & Böğ̈urtlen & 1.12 & Kuzluca & 1.24 & & \\
\hline
\end{tabular}

This new dataset was created to get the fractal dimension value of routes after collecting data from participants. In addition to this, dataset also was used to create a new variable in order to build new walkability index. For this reason, densities of all street segments were calculated using their fractal dimension values in ArcGIS tools. The created raster dataset was reclassified to have a score range of 1-5, without considering the literature suggestion as the fractal dimension value of all pictures were less than 1.3. Based on literature, values less than 1.3 or more than 1.6 were found to have low preference, and values between 1.3-1.5 were found to have high preference [42-45]. This new raster along with the previous 9 raster dataset was used to create new walkability index by combining these datasets. The walkability index was calculated by using the previous expression which was used to build walkability based on 3D+R index by simply adding the fractal dimension value.

In the fourth step, a survey was conducted to evaluate and validate the indices created in previous steps. The survey took place using 150 participants at the entrance of the Dutluk station. There were two entrances to the station and both were used periodically on the same day in order to get different information form the participants which lasted two months. The participants were people who walked to the station with the intention of using the train. The survey was kept as short as possible so that participants were willing to answer without worrying about missing the train. The survey consisted of general information regarding: gender, age, educational background, and the neighborhood where they live. Then, questions concerning the neighborhood based on density, diversity, design, and overall walkability. Then the participants were asked about the routes they took to reach the station, and then to draw the route and rate it based on aesthetic 
appeal and walkability. Before asking questions, there were pre-conditions that needed to be fulfilled. Dutluk station is located at the border of Pınarbaşı, Uyanış, Şenlik, Adnan Menderes, and Köşk neighborhoods and in order to qualify, participants must live in one of these neighborhoods. Beside this, participants should also use the station regularly by walking to it, and give information about the most frequent route they take to reach the station. Among those who qualified, only males agreed to participate while females on the other hand, refused. The age of participants ranged from 18 to 56 years and older. $42 \%$ of participants were aged between 26-40. Participant's education background varied from primary school up to graduate level with $55.3 \%$ of them having secondary education. As the pre-condition, participants lived in one of the above mentioned neighborhoods (Table 6).

Table 6. General information and participant's perceptions toward walkability

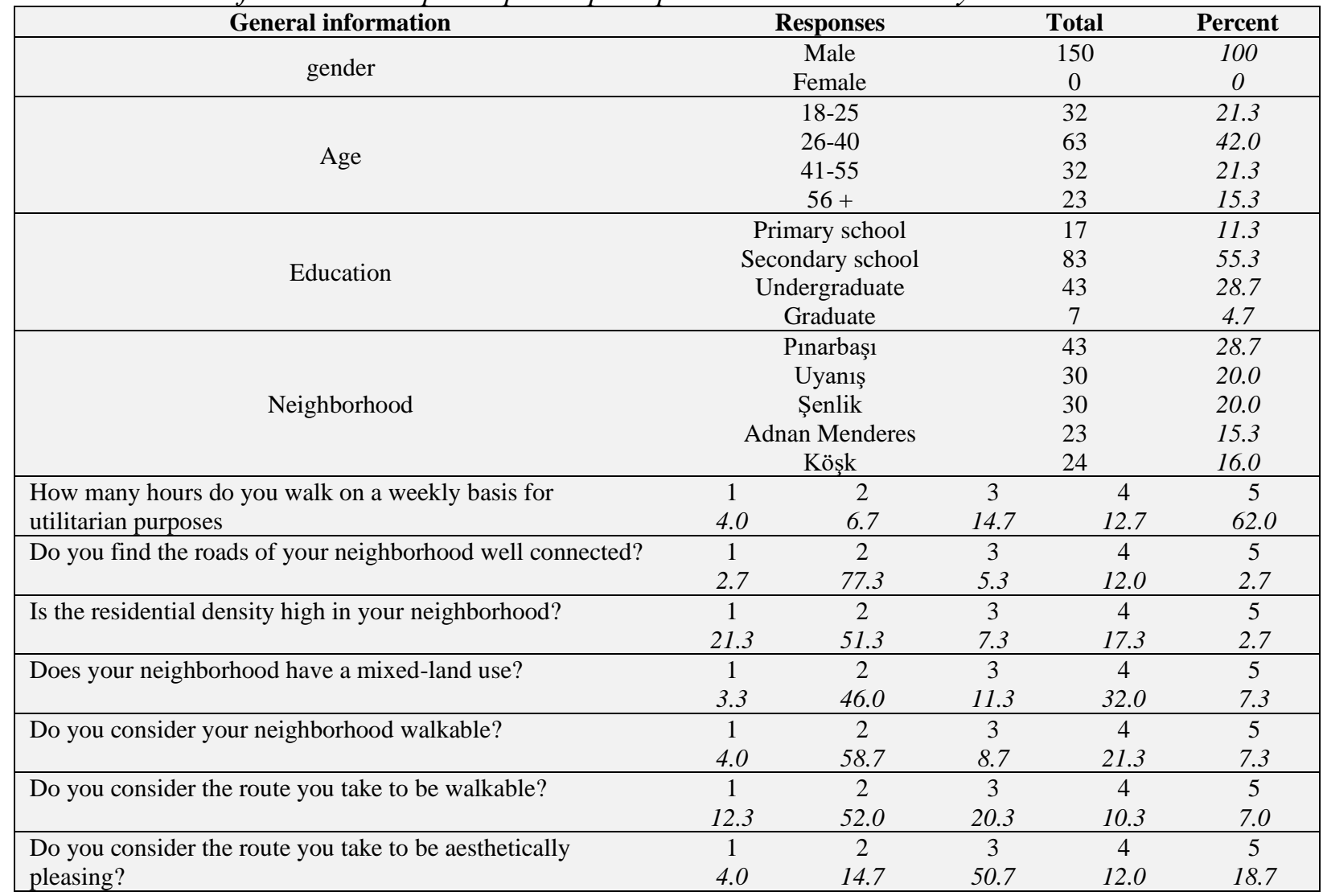

Participants were asked how many hours they walked on a weekly basis for utilitarian purposes. This question was used to obtain the amount of walking variable for future analysis. The participants were given the option to choose between less than one hour, one hour, two hours, three hours, and four hours or more. $62.0 \%$ indicated that they walked four hours or more on a weekly basis. Participants were asked questions concerning their neighborhood's density, diversity, design, and overall walkability. These questions were asked for the purpose of collecting data regarding participant's opinion and perception concerning these criteria. The participants were asked to complete a survey on a scale of one to five with one being strongly agree and five being strongly disagree with an option for those who had no opinion. Participants were provided with a map showing the station location and its 400-meter catchment area to draw their route inside this area toward the station. Then they were asked to rate their route based on walkability and aesthetic appeal. These questions were asked to collect data on user perception. The answers were on a scale of one to five with one being strongly agree and five being strongly disagree with an option for those who had no opinion. After collecting survey data, the routes of participants were used to create database in ArcGIS tools. Then routes were overlaid on the suitability databases created in the previous steps to get the value of each route based on walkability scores. The routes were also overlaid on the fractal dimension value database and their value and pictures were extracted from ArcGIS tools. The value for the routes ranged from lowest of 1.12 and highest of 1.22, and the mean fractal dimension value of the routes was 1.16 (Figure 7). Data concerning fractal dimension value of routes, density, diversity, design, and 
walkability of their neighborhood along with their opinion toward the routes was compiled and then added to the SPSS.

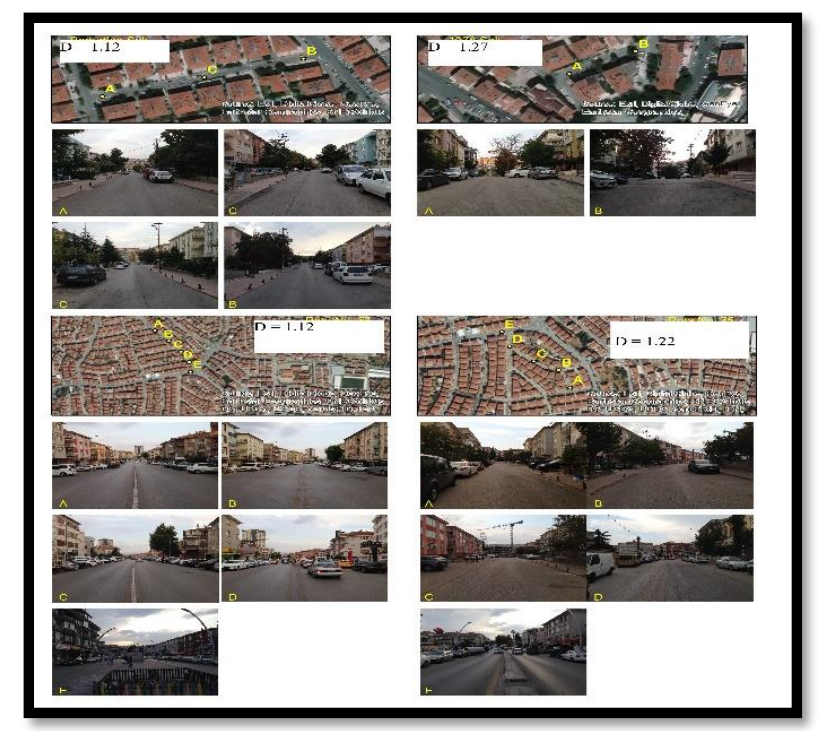

Figure 7. Pictures of street and routes

The suitability results using the 3D index at the scale of neighborhood and data on participant's opinions toward; intersection density, residential, land-use mix density, and walkability situation of their neighborhood were correlated with each other in the SPSS, and the p-value was used to determine the significance of the correlation. The result of 3D index's walkability also correlated with the amount of walking participant did on a weekly basis. Participant's answers regarding whether their neighborhood consists of more intersection or not were correlated with the result of 3D analysis about intersection density. There was positive correlation between two variables, as density analysis was able to predict participant's perceptions. The question about whether their neighborhood was heavily dominated with residential units or not were then correlated with the residential density analysis. The result showed no significant relation between two variables and residential density analysis was not successful at capturing participant's opinions. The question whether your neighborhood has a mixed land-use were also correlated with the landuse mix density analysis, and the result showed no significant correlation between these two variables. Finally, participant's opinions toward the walkability of their neighborhoods and the walkability analysis were correlated with each other. The results showed no significant correlation between these two variables, and the suitability analysis constructed by using 3D index was insufficient in determining the perception of pedestrians in this study. Walkability analysis result using 3D index was correlated with amount of walking participant did on a weekly basis. The result showed no significant relationship between them. The writer of this article attempted to collect the fractal dimension value of all streets in a neighborhood to add in 3D index, to see whether the fractal dimension value could change the result of correlation with participant perception or amount of walking. However, attempt was unsuccessful in determining the fractal dimension value in a given neighborhood scale. The suitability result of routes using $3 \mathrm{D}+\mathrm{R}$ index and data concerning participant's perception and opinions about the suitability of the routes they used correlated with each other. The relationship between two variables were found statistically significant, and this index was successful in determining the perception of the participants. The suitability result of routes using $3 \mathrm{D}+\mathrm{R}$ index and data about amount of walking on a weekly basis were correlated with each other. The result showed no significant relation between two variables. Lastly, the suitability index was constructed by using the fractal dimension value and data concerning participant's opinions about the suitability of their routes for walking were correlated with each other. Based on the result, this index was more successful in determining the participant's opinions toward the walkability of the routes (Table 7). The fractal dimension value of streetscape was correlated with the level of aesthetic appeal response participants gave to their routes. There was no significant correlation between them because the fractal dimension values were low and participants could not give a firm answer. It could be seen in the response they gave to the aesthetic appeal question with $50.7 \%$ giving no opinion, $30.7 \%$ rated it as not appealing and only $18.7 \%$ rated it as appleaing. 
Table 7. Correlation results

\begin{tabular}{|c|c|c|}
\hline \multicolumn{3}{|c|}{ Variables } \\
\hline \multirow{3}{*}{ Intersection density } & \multicolumn{2}{|c|}{ Participant opinion regarding intersection density } \\
\hline & Correlation & 0.166 \\
\hline & $P$-value & 0.042 \\
\hline \multirow{3}{*}{ Residential density } & \multicolumn{2}{|c|}{ Participant opinion regarding residential density } \\
\hline & Correlation & 0.031 \\
\hline & $P$-value & 0.705 \\
\hline \multirow{3}{*}{ Land-use mix density } & \multicolumn{2}{|c|}{ Participant opinion regarding land-use mix } \\
\hline & Correlation & -0.038 \\
\hline & $P$-value & 0.646 \\
\hline \multirow{3}{*}{ 3D index walkability } & \multicolumn{2}{|c|}{ Participant opinion regarding walkability of their neighborhoods } \\
\hline & Correlation & 0.113 \\
\hline & $P$-value & 0.167 \\
\hline \multirow{3}{*}{ 3D index walkability } & \multicolumn{2}{|c|}{ Participant amount of walking on a weekly basis } \\
\hline & Correlation & 0.041 \\
\hline & $P$-value & 0.621 \\
\hline \multirow{3}{*}{$3 \mathrm{D}+\mathrm{R}$ index walkability } & \multicolumn{2}{|c|}{ Participant opinion regarding walkability of their routes } \\
\hline & Correlation & 0.208 \\
\hline & $P$-value & 0.038 \\
\hline \multirow{3}{*}{$3 \mathrm{D}+\mathrm{R}$ index walkability } & \multicolumn{2}{|c|}{ Participant amount of walking on a weekly basis } \\
\hline & Correlation & 0.016 \\
\hline & $P$-value & 0.847 \\
\hline \multirow{3}{*}{$3 \mathrm{D}+\mathrm{R}$ index with fractal dimension } & \multicolumn{2}{|c|}{ Participant opinion regarding walkability of their routes } \\
\hline & Correlation & 0.238 \\
\hline & $P$-value & 0.017 \\
\hline \multirow{3}{*}{ Fractal dimension value of routes } & \multicolumn{2}{|c|}{ Participant level of aesthetic appeal } \\
\hline & Correlation & 0.052 \\
\hline & $P$-value & 0.530 \\
\hline
\end{tabular}

\section{RESULTS}

Significant research has been conducted on walkability through different disciplines such as public health, transportation planning, urban planning and design experts, each of which has made unique contributions to contemporary literature. Among the factors that affect walking behavior, built environment is considered utmost importance. A consensus has been reached among researchers that the components of the build environment such as density, diversity, and design has an effect on walking behavior. However, as the disciplines do not necessarily share common academic, language, concepts, and methods with each other, no consensus has been reached among them regarding how to characterize these components by using appropriate attributes. Disputes arouse concerning the attribute which is used to represent the design components of the built environment, as well as the expected results that comes from promoting walking behavior. Transportation planners have arguably made the greatest contributions to the study of walkability by conceptualizing and measuring the built environment. They use very straightforward variables to measure the built environment. The design dimension of the built environment is characterized by the number or density of street intersections as well as emphasizing the link function of the streets. The main reasons to use the number or density of street intersections are the difficulty of collecting data for the design variables or lack of data during the analysis. On the other hand, urban planners and designers argue that street intersections are not a good indicator to the design dimension of the built environment. Because this dimension needs to be characterized by micro scale attributes of the built environment, specifically the streetscape features as these variables have an effect on the perception and quality of the walking behavior. They implement these variables mostly in subjective analysis by emphasizing the place function of the streets.

The relationship between the built environment and walking behaviors is questioned in most studies over the amount of walking (pedestrian count or duration of this behavior). The aim of these studies is to find ways that promote and increase walking behaviors. Since the rate of walking for utilitarian purposes is much lower than other kinds of walking behaviors, there has been some difficulty in establishing a concrete 
relationship between the built environment and walking behaviors, with some studies indicating a relationship and some not. Data regarding the quality of walking behaviors needs to be implemented in both objective and subjective analysis in order to find the attributes of the built environment that correlate with these data. As the rate of participation in a survey is decreasing, finding a way to collect and quantify data on quality of walking for objective analysis could help researchers to promote this behavior because to do so, has both physical and psychological benefits.

In the context of arguments for the greater specificity of the relationship between the built environment and walking behavior, and being mindful of varying approaches from different diciplines, this study built indices and validated them by user perception with survey which was conducted at Dutluk station in Keçiören, Ankara. The fractal dimension value of streetscape was collected and implemented in the indices. Results show that the indices presented here captured perception of the pedestrian with increasing accuracy. Fractal dimension value of streetscape helped to implement the attributes of the built environment believed to effect the preference and perception of the pedestrian in the indices. It also helped to use the micro scale attributes of the built environment because those attributes are believed to have direct effect on walking behavior and experiences. Based on literature, individual urban design features seldom prove significant in walkability analysis and multiple design features have a collective impact on walking behaviors. The fractal dimension value of streetscape helped to implement streetscape's component in a single variable with the use of indices.

Walkability indices are built either using macro or micro scale attribute of the built environment instead of combining them. Considering that the built environment is a complex system without any dominant or clear scale, and that human activity occur within the range of scales inside the built environment; indices need to be built to show this situation by using macro and micro scale attributes working together. Fractal dimension value of streetscape enables researchers to put the micro and marco scale attributes of the built environment together to show how both attributes works simultaneously, and how they effect walking behavior. Creating walkable communities and indentifying the characteristics of walkable environment have become increasingly important for anyone responsible for citizen's welfare. Fractal dimension value of streetscape helped to create a more accurate database with regard this issue. It could also enable them to collect a variable which is not collected during the process. Fractal dimension value could also give new insight while conceptualizing other dimensions of the built environment which are density and diversity. In walkability studies high value of density and diversity are found to correlate with the amount of walking. Yet, there is no study to classify the value of these attributes and see if there is any specific range that correlates between them and the amount or quality of walking. The method in this study and the algorithm used here could be used to collect data in macro scale to better understand the condition of a neighborhood based on the fractal dimension value of its road and streets, and use the collected data in walkability indices to gauge the walkability situation in a neighborhood. Pictures of the streets could be acquired from the organizations which keep those records to get the value of the fractal dimension in a more time-efficient manner. Creating walkable paths around the station have become important and attempts with an emphasis on creating walkable environments. Fractal dimension value of streetscape could also be used to improve the overall quality of the paths used by the population. The algorithm used here can be used to break down the paths into the segments, and collect their fractal dimension value. These segments could be combined with the user's opinion to find out which segments of the routes have the most effect on the user's perception and their overall judements. Studying segment attributes of the built environment could be used to improve the quality of the routes based on design, and those attributes could then be implemented when designing new places.

\section{CONFLICTS OF INTEREST}

No conflict of interest was declared by the authors.

\section{REFERENCES}

[1] Litman, T., "Economic value of walkability", Transportation Research Board, 10(1): 3-11, (2003). 
[2] Leyden, K., "Social capital and the built environment: the importance of walkable neighborhood", American Journal of Public Health, 93(9): 1546-1551, (2003).

[3] Southworth, M., "Designing the walkable city", Journal of Urban Planning and Development, 131: 246-257, (2005).

[4] Litman, T., "Evaluating non-motorized transport benefits and costs", Victoria Transport Policy Institute, (2010).

[5] Rapoport, A., "Pedestrian street use: culture and perception", Moudon A.V., ed., Public streets for public use, Van Nostrand Reinhold Company, NY, (1991).

[6] Carwford, J., "Car free cities", The Netherlands: International Books, (2000).

[7] Ackerson, K.J., "A GIS approach to evaluating streetscape and neighborhood walkability", Oregon University, unpublished master thesis, (2005).

[8] Frank, L., Engelke, P., and Schmid, T., "Health and community design: the impact of the built environment on physical activity", Island Press, Washington. D.C, (2003).

[9] Leslie, E., Butterworth, L., and Edwards, M., "Measuring the walkability of local communities using geographic information systems data", The $7^{\text {th }}$ international conference on walking and livable communities, Melbourne, Australia, (2006).

[10] Leslie, E., Coffee, N., Frank, L., Owen, N., Bauman, A., and Hugo, G., "Walkability of local communities: using geographic information systems to objectively assess relevant environmental attributes", Health \& Place, 13: 111-122, (2007).

[11] Owen, N., Cerin, E., Leslie, E., duToit, L., Coffee, N., Frank, L., Bauman, A.E., Hugo, G., Saelens, B., and Sallis, J.F., "Neighborhood walkability and the walking behavior of Australian adults", American Journal of Preventive Medicine, 33(5): 387-395, (2007).

[12] Saelens, B., and Handy, S., "Built environment correlates of walking: a review", Journal of The American College of Sport Medicine, 31(8): 550-566, (2008).

[13] Clifton, J.K., Livi Smith, D.A., and Rodriguez, D., "The development and testing of an audit for the pedestrian environment", Landscape and Urban Planning, 80: 95-110, (2007).

[14] Kelly, C.E., Tight, M.R., Hodgson, F.C., and Page, M.W., "A comparison of three methods for assessing the walkability of the pedestrian environment", Journal of Transport Geography, 19: 1500-1508, (2011).

[15] Bauman, A., Reis, R., Sallis, J., Wells, J., Loos, R., and Martin, B., "Correlates of physical activity: why are some people physically active and others not?", Lancet Physical Activity Series, 380: 258-271, (2012).

[16] Sallis, J., Cervero, R., Ascher, W., Henderson, K., Kraft, K., and Kerr, J., “An ecological approach to creating active living communities", Annual Revive Public Health, 27: 297-322, (2006).

[17] Halu, Z., and Yürekli, F., "Yürünebilirlik kavramı ve kentsel mekanlarda yürüme”, İTU Dergisi, 10(2): 29-38, (2011).

[18] Baranowski, K., Cullen, W., Nicklas, T., Thompson, D., and Baranowski, J., "Are current health behavioral change models helpful in guiding prevention of weight gain efforts?", Obesity Research, 11: 23-43, (2003). 
[19] Sallis, J., "Measuring physical activity environments: a brief history", Journal prevention Medicine, 23(4s): 86-92, (2009).

[20] Alfonzo, M.A., "To walk or not to walk? The hierarchy of walking needs", Environment and Behavior, 37(6): 808-836, (2005).

[21] Giles-Corti, B., and Donovan, R. J., "The relative influence of individual, social and physical environment determinants of physical activity", Social Science \& Medicine, 54: 1793-1812, (2002).

[22] Handy, S., Boarnet, M., Ewing, R., and Killingsworth, R., "How the built environment affects physical activity: views from urban planning?", American Journal of Preventive Medicine, 23(2s): 64-73, (2002).

[23] Thornton, L.E., Pearce, J.R., and Kavanagh, A.M., "Using geographic information systems (GIS) to assess the role of the built environment in influencing obesity", International Journal of Behavioral Nutrition and Physical Activity, 8:7, (2011).

[24] Duncan, M., Winkler, E., Sugiyama, T., Cerin, E., duToit, L., Leslie, E., and Owen, N., "Relationship of land use mix with walking for transport: do land uses and geographical scale matter?", Journal of Urban Health: bulletin of the New York Academy of Medicine, 87(5): 782795, (2010).

[25] Cervero, R., and Kockelman, K., "Travel demand and the 3 Ds: density, diversity, and design", Transportation Design D, 2: 199-219, (1997).

[26] Frank, L., Schmid, T., Sallis, J., Chapman, J., and Saelens, B., "Linking objectively measured physical activity with objectively measured urban form: findings from SMARTRAQ", American Journal of Preventive Medicine, 28(2S2): 117-125, (2005).

[27] Moudon, A. V., and Lee, C., "Walking and bicycling: an evaluation of environmental audit instruments", American Journal of Health Promotion, 18(1): 21-37, (2003).

[28] Lee, C., and Moudon, A.V., "Physical activity and environment research in the health field: implications for urban and transportation planning practice and research", Journal of Planning Literature, 19(2): 147-181, (2005).

[29] Lee, C., and Moudon, A.V., "The 3Ds + R: quantifying land use and urban form correlates of walking", Transportation Research Part D, 11: 204-215, (2006).

[30] Ewing, R., Hajrasoullha, A., Neckerman, K. M., Purciel-Hill, M., and Greene, W., "Streetscape features related to pedestrian activity", Journal of Planning Education and Research, 36(1): 5-15, (2016).

[31] Yin, L., "Street level urban design qualities for walkability: Combining 2D and 3D GIS measures", Computers, Environment and Urban Systems, 64: 288-296, (2017).

[32] Ramsey, A., "A systematic approach to the planning of urban networks for walking”, The greening of urban transport: Planning for walking and cycling in western cities, R. Tolley, ed., Belhaven Press, London, (1990).

[33] Adkins, S. A., Dill, J., Luhr, G., and Neal, M., "Unpacking walkability: testing the influence of urban design features on perceptions of walking environment attractiveness", Journal of Urban Design, 17(4): 499-510, (2012). 
[34] Cervero, R., "Built environments and mode choice: toward a normative framework", Transportation Research Part D, 7: 265-284, (2002).

[35] Yin, L., "Assessing walkability in the city of buffalo: application of Agent-Based Simulation", Journal of Urban Planning and Development, 139: 166-175, (2013).

[36] Ewing, R., and Cervero, R., "Travel and the built environment: A synthesis", Transportation Research Record, 01-3515: 87-144, (2001).

[37] Relph, E., "The modern urban landscape: 1880 to the present”, Croom Helm, London \& Sydney, (1987).

[38] Jones, P., Marshall, S., and Boujenko, N., "Creating more people-friendly urban streets through 'link and place' street planning and design”, IATSS Research, 32(1): 14-25, (2008).

[39] Jacobs, J., "The death and life of great American cities", Random House, New York, (1961).

[40] Lynch, K., "The image of the city”, The MIT Press, (1960).

[41] Giles-Corti, B., Timperio, A., Bull, F., and Pikora, T., "Understanding physical activity environmental correlates: Increased specificity for ecological models", Exercise Sport Science Revive, 33(4): 175-181, (2005).

[42] Spehar, B., Clifford, C.W.G., Newell, B.R., and Taylor, R.P., "Universal aesthetic of fractals", Computers \& Graphics, 27: 813-820, (2003).

[43] Hagerhall, C.M., Purcell, T., and Taylor, R., "Fractal dimension of landscape silhouette outlines as a predictor of landscape preference", Journal of Environmental Psychology, 24: 247-255, (2004).

[44] Cooper, J., and Watkinson, D., "Fractal analysis and perception of visual quality in everyday street vistas", Environmental and Planning B: Planning and Design, 37: 808-822, (2010).

[45] Cooper, J., and Oskrochi, R., "Fractal analysis of street vistas: a potential tool for assessing levels of visual variety in everyday street scenes", Environmental and Planning B: Planning and Design, 35: 349-363, (2008).

[46] El-Darwish, I.I., "Fractal design in streetscape: rethinking the visual aesthetics of building elevation composition", Alexandria Engineering Journal, (2019).

[47] Salingaros, N.A., "Twelve lectures on architecture: algorithmich sustainable design", Solingen: Urban-Verlag, (2010).

[48] Lotfi, S., and Koohsari, M.J., "Neighborhood walkability in a city within a developing country", Journal of Urban Planning and Development, 137(4), (2011). 